\title{
As porosidades do campo literário nacional: a emergência da literatura pós-Holocausto no Brasil
}

\section{The porosities of the national literary field: the emergence of post- Holocaust literature in Brazil}

Joanna M. Moszczynska*

Universität Regensburg

joanna.moszczynska@ur.de

\begin{abstract}
RESUMO: Neste artigo, que dialoga com as ideias centrais da pesquisa de doutorado concluída por mim em 2020, proponho pensar a literatura brasileira pós-Holocausto como uma literatura emergente dentro do campo literário do Brasil. A emergência, conceituada como um potencial e um ato de ruptura, tem sido condicionada pela pesquisa teórico-crítica que viu a literatura em questão como marginalizada, étnica e alheia às realidades brasileiras. Para superar tal confinamento, contextualizo-a como um conjunto literário autônomo e heterogêneo que irrompe as fronteiras entre as noções da literatura brasileira, da literatura judaica e da literatura do Holocausto. Além disso, como uma característica particular e um parâmetro primário da sua emergência, chamo atenção à presença de memórias entrelaçadas de várias histórias de violência que provocam uma reflexão acerca de novas maneiras de rememoração no Brasil pós-ditatorial.
\end{abstract}

PALAVRAS-CHAVE: Emergência. Campo literário. Literatura pós-Holocausto. Memória multidirecional.

ABSTRACT: In this article, which dialogues with the central ideas of the doctoral research I completed in 2020, I propose to think of post-Holocaust Brazilian literature as an emerging literature within the literary field of Brazil. The emergence, conceptualized as a potential and an act of rupture, has been conditioned by theoretical-critical research that saw this literary expression as marginalized, ethnic and alien to Brazilian realities. In order to overcome this confinement, I contextualize it as an autonomous and heterogeneous literary ensemble that erupts the boundaries between the notions of Brazilian literature, Jewish literature and Holocaust literature. In addition, as a particular characteristic and primary parameter of its emergence, I draw attention to the presence of intertwined memories of various stories of violence which provoke a reflection about new ways of remembrance in post-dictatorial Brazil. KEYWORDS: Emergence. Literary field. Post-Holocaust Literature. Multidirectional Memory.

\footnotetext{
* Assistente de pesquisa (Pós-doutorado) no Centro de Estudos da Área Internacional e Transnacional (CITAS) da Universidade de Regensburg - Alemanha.
} 


\section{Introdução}

Partindo dos achados da minha pesquisa de doutorado que concluí em 2020, apresento a literatura brasileira pós-Holocausto como uma literatura emergente a partir da qual se deixa repensar o campo literário do Brasil contemporâneo e refletir sobre novas perspectivas para as dinâmicas e diálogos que ocorrem dentro deste campo. Enquanto a pesquisa teórico-crítica dos últimos 35 anos fez um grande esforço para trilhar o caminho da legitimação do tema do Holocausto ${ }^{1}$ nas letras nacionais - o tema presente sobretudo em autores e autoras judias, como demonstrou a pesquisa biográfico-quantitativa -, observa-se que a dita temática não resistiu a uma marginalização tripla: dentro da produção literária reconhecida como brasileira, dentro da produção literária reconhecida no Brasil como judaica e, finalmente, dentro daquela que se costuma chamar de literatura do Holocausto. Observando as condições de cada uma destas marginalizações, nota-se que elas podem ser superadas através de uma nova conceitualização de um conjunto de textos, cuja emergência é relacionada com o boom da memória a partir dos anos 80 no Ocidente e no Brasil a partir do novo milênio. Portanto, o seguinte artigo pensa novos ramos conceituais da literatura pósHolocausto no Brasil, tratando de seu carácter emergente e da estética de memórias entrelaçadas, que desestabilizam as noções dominantes que se têm criado acerca da representação do genocídio judaico no campo literário nacional atual.

Primeiro, introduz-se uma possível definição e datação da literatura pósHolocausto do Brasil, da qual distinguem-se duas fases: 1946-1985 e 1986 até hoje em dia. Logo, definem-se as suas propriedades de literatura emergente, com base nas contribuições de Raymond Williams (1977), Wlad Godzich (1988) e Jean Bèssiere (2004). Ela é uma literatura que, se não for o agente decisivo, propiciou o boom (tardio) da memória do Holocausto no Brasil. Implodindo tanto o campo literário do Brasil como o campo transnacional da literatura do Holocausto, ela desafiou os espaços canônicos

\footnotetext{
1 O termo "Holocausto" abrange todos os aspectos da política de extermínio e perseguição perpetrados pelo nacional-socialismo desde a chegada ao poder dos assassinatos em massa durante a Segunda Guerra Mundial. Essa definição costuma incluir, portanto, a perseguição tanto dos judeus, como adversários políticos, homossexuais, Sinti e Roma, Testemunhas do Jeová e outros. Mesmo assim, a perseguição e assassinato dos judeus europeus é considerada a parte central do 'Holocausto', que não se pode comparar com os outros crimes cometidos pela e durante a Alemanha Nazista. Não há consenso quanto à inclusão dos crimes cometidos pelo regime stalinista, inclusive contra a população judaica. Em comunidades judaicas, no lugar de Holocausto, costuma usar-se o termo Shoah para se referir exclusivamente à Destruição dos judeus europeus. Neste artigo, não rejeito o paradigma étnico da literatura pós-Holocausto no Brasil, já que esta é feita principalmente pelos autores e autoras judías brasileiras, mas insisto em repensar a etnicidade no contexto da literatura.
} 
dos dois e atualmente torna-se o objeto de estudo cada vez mais visível e de recepção cada vez mais diversificada, tanto no Brasil como no exterior. Por conseguinte, é possível caracterizá-la segundo sua propriedade de ruptura e de potência (como potencial e como força). Logo, observa-se como o status desta literatura como literatura emergente viu-se sujeito à legitimação literária e cultural a partir dos anos 1980. Argumenta-se que a pesquisa dos últimos 35 anos criou noções a respeito do tema do Holocausto na literatura brasileira, que uma vez sistematizadas revelam um certo padrão teórico-analítico a ser tomado em conta na definição da emergência. Finalmente, chama-se atenção aos discursos polimorfos que se inscrevem no caráter emergente desta literatura e demonstram um engajamento dela com distintas memórias coletivamente traumáticas postas em diálogo através de vários recursos estéticos. Embora existam pesquisas que têm analisado alguns exemplos singulares de memórias entrelaçadas do Holocausto, da ditadura militar e do colonialismo na literatura brasileira, elas não se atreveram a colocar em funcionamento o método da memória multidirecional (ROTHBERG, 2009) que, como se debate aqui, revela o polimorfismo mnemônico como um dos traços centrais e persistentes da literatura em questão: a literatura pós-Holocausto no Brasil.

\section{0 que é literatura pós-Holocausto no Brasil}

Na definição abrangente de Roskies e Diamant (2013, p. 2), a literatura do Holocausto compreende todas as formas de escrita e em qualquer língua, que têm moldado a memória pública do Holocausto e têm sido moldadas por ela. $\mathrm{O}$ corpus teórico-crítico sobre esta literatura é uma das áreas literárias mais prolíferas e versáteis no Ocidente ditada tanto pelo conteúdo como pela forma, pelas perguntas sobre o que é representado e como é representado. Ao mesmo tempo, reconhece-se a necessidade de recorrer ao aspecto biográfico dos autores e autoras - um método hoje em dia bastante polêmico -, ou, em outras palavras, à posicionalidade, pois, como observa Berberich (2006, p. 568), os antecedentes como a origem, o histórico pessoal e profissional, como também a motivação, inevitavelmente afetam os modos de se lidar com a memória coletivamente traumática do genocídio judaico.

Embora o carácter transnacional do crime nazista tenha ditado uma deslocação dos seres humanos envolvidos, principalmente a re-constelação da diáspora judaica, exige-se, entre outros, que haja um reconhecimento da responsabilidade dos 
agressores nazistas e seus colaboradores, assim como um reconhecimento das vítimas de vários grupos étnicos e minoritários e de várias nacionalidades (ASSMANN 2010 , p. 97). Estes dois paradigmas, o transnacional e o nacional, também se refletem na crítica e na teoria da literatura do Holocausto, embora elas mantenham-se bastante reservadas quando se trata da produção literária vinda não do Ocidente setentrional. Fazer desta versatilidade um imperativo ético e teórico contribuiria para uma descentralização da visão hegemônica sobre a literatura do Holocausto e chamaria a atenção para aqueles conjuntos da literatura do Holocausto periféricos ou ainda não reconhecidos, como é o caso do Brasil.

Dentro da assim definida literatura do Holocausto, é possível distinguir a pertencente a ela a literatura ficcional pós-Holocausto que exclui efetivamente o testemunho de sobrevivência e o diário do Holocausto etc., e se caracteriza sobretudo por uma reflexão pós-Holocausto que fornece respostas (e mais perguntas) às demandas pós-modernas da representação e da leitura do passado traumático coletivo. O conceito da literatura pós-Holocausto implica que haja textos que não outorgam uma centralidade à experiência do espaço concentracionário ou do gueto, mas são textos que se ocupam com os efeitos duradouros e traumáticos do evento, tanto em sobreviventes como em gerações posteriores.

O desenvolvimento da literatura pós-Holocausto no Brasil pode dividir-se em duas fases: 1946-1985, a fase de conscientização, e de 1986 até hoje em dia, a fase da pós-memória, que eu efetivamente reconheço como a de emergência do conjunto literário da literatura pós-Holocausto.

Os primeiros textos não-documentais aparecem já a partir dos anos 40 no Brasil, em português e em ídiche. Eles pertencem aos autores da 1,52 e da segunda geração de imigrantes judeus que chegaram à América Latina nas primeiras três décadas do século XX. Geralmente, os imigrantes contam as histórias de exílio no contexto do antissemitismo na Europa e dos pogroms no Império Russo, narram a aculturação e as expectativas de uma melhor vida econômica do outro lado do Atlântico, integrando suas preocupações pelo destino dos parentes e amigos que ficaram na Europa. Esta fase caracteriza-se pela presença de vozes semiautobiográficas e memorialistas. O Holocausto é mediado pelas notícias da rádio e dos jornais, mas não nomeado; ele é retratado apenas tangencialmente ou por

\footnotetext{
${ }^{2}$ A 1,5 geração refere-se em princípio aos sobreviventes infantis do Holocausto, mas encontra sua aplicação também no contexto do exílio e da emigração infantil (Cf. SULEIMAN, 2002).
} 
alusões; velado pelo silêncio integrado na narrativa para expressar o indizível e o incompreensível; os sobreviventes são representados como refugiados, forasteiros traumatizados pela guerra. Esta é uma literatura de sensibilização e de conscientização dos crimes nazistas direcionada contra a população judaica europeia. Como pioneiro considera-se o conto do falecido em 2018 Jacó Guinsburg, "O Retrato", publicado em 1946 na revista juvenil O Reflexo (IGEL, 1997, p. 218). Além do professor Guinsburg, é preciso destacar aqui Samuel Rawet, Zevi Ghivelder, Elizer Levin, Clarice Lispector (Cf. AIZENBERG, 2015; MOSZCZYNSKA, 2017), Moacyr Scliar e Judith Grossmann. Nos anos 70. também se publicam os primeiros testemunhos de sobrevivência.

Ao lado de um aumento significante de número dos relatos testemunhais publicados no Brasil (tanto escritos em português como as traduções de obras canônicas da literatura testemunhal), a partir dos anos 1990 observa-se o surgimento de novas gerações de escritoras e escritores e com isso uma cristalização decisiva da literatura ficcional pós-Holocausto. Esta literatura data-se já a partir de 1986, quando se publica o conto de Moacyr Scliar, "Na minha suja cabeça, o Holocausto", um exemplo exímio da pós-memória da Segunda Geração, flexionada pela transgressão e pelo tropo da história como pesadelo. Logo, os textos a seguir, contos e romances, escritos em português por autores e autoras judaico-brasileiras, de um cronotopo predominantemente brasileiro, possuem uma variedade formal e estética, embora haja certos elementos que se repitam, convergindo-os num corpus de características discerníveis, como: autorreflexividade, metaficção, tematização da identidade, do corpo e da memória judaica com enfoque no presente, mistura de pactos ficcional e autobiográfico, tematização da transmissão, do trauma e do luto, assim como a estética de transgressão (tributária da obra de Scliar). Todas essas características fazem com que não apenas textos individuais sejam passíveis de pesquisas hermenêuticas, narratológicas e comparatistas com instrumentos desenvolvidos na área dos estudos do Holocausto, mas também como um conjunto, cuja emergência cria uma intersecção entre a literatura brasileira, a literatura judaica e a literatura do Holocausto, que desestabiliza as noções tradicionais e comuns do campo literário do Brasil.

Além disso, na mesma altura forma-se no Brasil um novo campo de pesquisa da literatura do Holocausto, representado por um círculo restrito de acadêmicos 
especialistas sobretudo em literaturas judaicas ou estudos brasileiros e portugueses. ${ }^{3}$ Este círculo se alarga apenas na segunda década do século XXI, quando o debate sobre memórias transnacionais e viajantes aumenta, e a produção literária sobre o Holocausto feita no Brasil torna-se objeto de interesse cada vez mais cobiçado internacionalmente. Além disso, devido às políticas de internacionalização literária, o Brasil ganha visibilidade nas festas e feiras do livro, encontros com autores, bem como através das traduções (também financiadas pelas instituições governamentais), o que efetivamente começa a afetar de maneira positiva a recepção dos autores e das autoras judaico-brasileiras e dos textos sobre o Holocausto. Quanto ao campo cultural interior, a literatura pode tirar proveito da crescente conjuntura da memória pública do Holocausto no Brasil, devido à abertura de novos monumentos, iniciativas acadêmicas (como o projeto ArqShoah) e do Museu do Holocausto em Curitiba, Paraná. Isso sugere, que um conjunto literário como aquele em questão não se defina apenas pelo seu valor literário, nem exista por si próprio, mas se encontra sujeito às relações estruturais econômicas e sociais que regem o campo cultural no qual ele emerge (Cf. BOURDIEU, 1993).

\section{Literatura emergente}

Emergência dentro de um campo literário, analogamente à emergência cultural definida por Raymond Williams (1977, p. 123), refere-se aos "novos" significados, valores, práticas e relações que são continuamente criados e recebidos em relação com o que é dominante e comumente estabelecido. Além de sujeita às relações objetivas de poder que tomam lugar no dado campo literário, ela deve ser vista como uma caracterização afirmativa de um conjunto literário de substância particular, de características discerníveis. Um conjunto literário é definido como emergente porque surge depois de outros conjuntos literários, cujas condições - dados culturais, históricos, ideológicos, sociais etc. - ela irrevogavelmente compartilha, embora possa abordar de maneira distinta, através do processo de seleção e de reorganização, propiciando uma mudança ou uma ruptura. No entanto, como sublinha Godzich (1988, p. 35), não se trata da emergência no sentido econômico da ideologia tercermundista

\footnotetext{
${ }^{3}$ Penso aqui nos pioneiros nesta matéria, como Regina Igel, Berta Waldman, Nelson H. Vieira; também Nancy Rozenchan, que é professora de literatura hebraica.
} 
de uma literatura em desenvolvimento e então inferior ao que se entende como uma literatura já "emergida". O ponto de Godzich é que literaturas emergentes não cabem facilmente em uma compreensão dentro das visões hegemônicas da literatura, dentro de suas orientações metodológicas e teoréticas com as quais se estabelecem os cânones e as literaturas nacionais. A visão hegemônica, nesse sentido, refere-se ao conhecimento disponível no tempo e no espaço e à inserção da literatura neste tempo e espaço que, em palavras de Godzich, é regido pelo "theoretical gaze" (1988, p. 31), hoje em dia desafiado principalmente pela crítica pós-colonial e feminista. O titular principal do "theoretical gaze" considera-se o Ocidente setentrional, de onde, nota bene, origina quase toda a literatura ou pelo menos todo o cânone e a teoria pósHolocausto. Disso resulta um impasse para se considerar como 'emergente' uma, ou qualquer, literatura pós-Holocausto. Será uma literatura pós-Holocausto feita no Brasil, uma literatura emergente? Como se define sua incompreensão - o parâmetro da emergência - dentro do campo literário do Brasil, se existem já instrumentos com os quais se possa estudá-la? Em que consistiria tal emergência, se a visão hegemônica ocidental (uma que define o que é e o que não é literatura e teoria pósHolocausto), caso ela quiser prestar atenção aos autores do Brasil e seus textos, reconhecesse a existência da literatura pós-Holocausto do Brasil? O mero fato de ela não for reconhecida como tal pode atestar o seu carácter emergente? Como observou Godzich, há casos de autores do "Terceiro Mundo", ao qual atualmente nos referiríamos como Sul Global, que escrevem de maneira não-emergente, como, por exemplo, V.S. Naipaul. Será esse o caso dos autores da literatura pós-Holocausto no Brasil? Emergência é então questão de estética ou de recepção?

Tais perguntas tornam-se ainda mais pungentes, quando se recorda que o conceito de emergência encontra-se contextualizado dentro da crítica pós-colonial e pensamento decolonial, nos quais o lugar do sofrimento e do trauma judaicos é no mínimo ambivalente (Cf. CHEYETTE, 2000, p. 54-55; ROTHBERG, 2009, p. 93; SICHER \& WINEHOUSE, 2021, p. 232). Embora, até então, tal ambivalência não tenha sido extensivamente abordada no Brasil, salvo as pesquisas sócio-históricas de Monica Grin e Michel Gherman (2016), ela inevitavelmente coloca uma série de assuntos difíceis para o campo literário do Brasil, que se posiciona como um espaço de valorização da denúncia sócio-política e de afirmação nacional face à literatura do Norte Global, primariamente europeia. 
Tudo isso sugere que a emergência precise ser pensada numa perspectiva relacional e condicional dentro dos estudos literários que não são uma argamassa rígida de hierarquias e de conhecimentos estáveis, embora possa parecer o contrário, mas uma disciplina expansível e gerenciada pelo potencial e pelo ato, e que precisa ficar atenta às novas condições e regimes das forças econômicas e sociais que agem sobre ela. Assim, colocar a literatura pós-Holocausto do Brasil na intersecção entre a literatura brasileira, a literatura judaica e a literatura do Holocausto antecipa tal perspectiva relacional e condicional, porque implica uma coexistência objetivamente igualitária dos três conjuntos sendo interrompidos pelo corpus em questão que exige deles que interajam entre si, criando dessa maneira novas noções do campo literário brasileiro e pondo em xeque as qualidades não tão óbvias do emergente e do canônico (sinônimo de dominate, estabelecido e/ou compreensível). Através da interseção, para não ser confundida com o conceito sociológico da intersecionalidade, descobre-se que as fronteiras entre vários conjuntos literários são por si porosas, e os elementos emergentes, como o conjunto em questão, podem colocar à mostra tais porosidades, assim como irromper as noções com as quais se constroem a teoria e a historiografia literárias, até a própria noção vigente do literário.

Não há dúvida de que o discurso literário sobre o Holocausto no Brasil não pertence às narrativas dominantes que criam, reproduzem ou revisam as ideias acerca da sociedade e da história brasileiras. No entanto, se pensado em termos de emergência como a potencialidade da literatura de gerar obras que vão ativamente atualizando as noções do presente e do passado e a relação entre os dois, convida para um plural entendimento histórico dos movimentos migratórios, do exílio pré- e pós-bélico, e em geral do Brasil no século XX, assim como da presença judaica diaspórica na pós-modernidade, no país e no mundo. Ela pode ser vista, portanto, como um gerador de novos conhecimentos e novas subjetividades e nisso também assente sua ação desestabilizadora, ou pelo menos, seu potencial para a tal ação. Em palavras de Bèssiere (2004, p. 53), literatura emergente seria justamente uma literatura de potência e de ato ("de la puissance et de l'acte"), e que, para ser reconhecida como emergente, precisa de afirmação de sua identidade e sua identificação (BÈSSIERE, 2004, p. 49); algo que no caso da literatura pós-Holocausto do Brasil está justamente por acontecer.

Em suma, falar de uma literatura emergente a respeito da expressão judaicobrasileira pós-Holocausto significa (pelo menos) três coisas. Primeiro, significa 
reconhecer as condições de sua presença dentro e na interseção dos mencionados conjuntos literários. Segundo, implica consolidar uma relação intertextual desta literatura com seus antecedentes e seus contemporâneos (brasileiros e nãobrasileiros, testemunhos, literatura autobiográfica dos sobreviventes e dos bystanders, literatura da Segunda e da Terceira Geração, outras ficções pósHolocausto, cânone da literatura do Holocausto) e em relação com o futuro para o qual este fenômeno se deixa projetar: futuro da memória pública da Destruição judaica no Brasil e futuro da pesquisa sobre a pós-memória e seus veículos no contexto global, enriquecido pela contribuição brasileira. Finalmente, significa abrir um novo espaço dentro do cronotopo pós-colonial e pós-ditatorial brasileiro, o espaço onde a ficção pós-Holocausto possa dialogar com outras "velhas" ficções nacionais e participar legitimamente do campo literário do Brasil.

A emergência da literatura em questão é condicionada pela teoria e crítica literária. O exame da pesquisa fornecida por Regina Igel, Nelson H. Vieira, Robert DiAntonio, Berta Waldman, Márcio Seligmann-Silva e Nancy Rozenchan, acadêmicos pioneiros nesta matéria, revela uma série de argumentos que se alinham em princípio a três grandes grupos temático-conceituais: etnicidade, marginalidade e diferença/distância, e que revelam um único objetivo comum compartilhado, nomeadamente, da legitimação da expressão pós-Holocausto perante o campo literário do Brasil.

\section{Do “panorama desolador” à afirmação do novo conjunto literário}

A legitimação da literatura emergente concentrou-se em particular no paradigma local étnico, por assim dizer, e subordinou a produção literária pósHolocausto à expressão judaica na literatura brasileira. Além disso, também demonstrou uma tendência a destacar a natureza marginal deste tema, gerada pelo hiato entre sua fundação epistemológica e a percepção cognitiva do público brasileiro.

A partir dos finais dos anos 80 , a etnicidade serviu como referência central para afirmar a presença dos escritores e das escritoras no campo literário brasileiro e a formação do que se poderia chamar de literatura judaica do Brasil. A problematização da dinâmica entre o brasileiro e o judaico coincidiu com a problematização do conceito da "literatura judaica latinoamericana" e da existência de uma identidade "judaica latinoamericana" que surgiu nos anos 1980 entre os acadêmicos hispano-americanos 
(GOLDBERG, 2000, p. 213). A onda de estudos sobre identidades na América Latina revelou uma necessidade de delinear e refletir as extensões e os limites do pertencimento, ou não, judaico. As confluências e as tensões entre o judaico e o brasileiro mantiveram-se bastante centrais até na pesquisa mais recente, que buscou ressaltar o papel da literatura na criação dos "entrelugares" da condição aparentemente incompatível:

Quando se pensa a conjugação do ser judeu e do ser brasileiro, vê-se que são termos que não caminham juntos. Cada um deles carrega um conjunto de referentes ligados a realidades históricas, políticas, sociais e afetivas diferentes. Mas é possível, e a literatura o faz, escavar os entrelugares, o ponto de intersecção de identidades, línguas, culturas, tradições, que evita a polaridade de binários, forjando uma terceira posição que reconhece as duas outras, mas flui em trilho próprio. (WALDMAN, 2003, p. XX)

[...] Brazilian Jewish writers provide added dimension to the dramatization of being culturally the same as Brazilians but also different as Jews, implying that cultural ethnicity and identity are implicitly an in-between, an entrelugar, an ever-changing or altering condition and ironically so inherent to the modus operandi of Brazil's national cannibalistic identity and ethos [...]. Within their narrative quests, they claim a public space for the inclusion of difference by pointing to the gaps, fissures, and fractures related to cultural alterity. In this way, Brazilian Jewish writing reflects the much-needed sociopolitical principles of equity and ethics in the formation of ethnic identity and multiple identities. (VIEIRA, 2009, p. LXXV-LXXVI)

O Holocausto fez parte da agenda dos estudos da literatura judaica, já que "Holocaust is an event that many Jewish and a few non-Jewish writers in Brazil draw on to relate their memory and understanding of genocide." (VIEIRA, 2009, p. LI) No entanto, ele foi associado à experiência concentracionária, ou à memória dela, mediada pelo testemunho, cujo valor é ético antes de estético. Em contraste, a ficção - com a persistência da convicção de que são raras as escritas ficcionais que abordam a temática (ROZENCHAN, 2001, p. 367) - foi colocada entre os temas da literatura judaica. Embora tal enfoque tenha enfatizado o carácter particular do Holocausto como um crime contra a população judaica europeia, resultou pouco elucidativo para a cognição das extensões da sua representação nas letras brasileiras, não deu conta do fenômeno na sua plenitude do corpus literário, nem forneceu suficientes aproximações comparatistas com outras literaturas judaicas, com a literatura global do Holocausto ou até com a literatura brasileira não-judaica. 
Colocar o Holocausto como um tema literário dentro da categoria da literatura judaica é ainda problemático quando se averigua os exemplos individuais dos autores cujas obras classifico como literatura pós-Holocausto. Penso aqui primeiro no autor da primeira fase (1946-1985), Samuel Rawet, o caso mais famoso de escritor que se tinha repetidamente posicionado contra a tradição judaica e talvez por isso tenha demorado até ele ser redescoberto como autor judeu e revalorizado como autor da língua portuguesa. Logo, também lembro que Clarice Lispector faz parte da literatura judaica - isso primariamente a partir dos anos 1980 com os primeiros estudos da presença da tradição judaica na sua obra fornecidos, entre outros, por Nelson Vieira - e ao mesmo tempo conquistou seu lugar no panteão literário brasileiro. A própria escritora, por várias razões, tinha demorado em assumir publicamente sua judeidade. Mais recentemente surge Michel Laub, cuja obra de jeito nenhum qualifica-se como literatura judaica, embora o romance Diário da queda (2011) aborde as questões da memória, também memória judaica, depois do Holocausto. O mesmo se pode dizer sobre Rafael Cardoso, autor de O Remanescente, um exemplo do romance histórico pós-Holocausto que resiste ser classificado como literatura judaica.

Ao lado da etnicidade, na pesquisa surgiu também a questão da diferença, que colocou o Holocausto como uma experiência e um tema alheio à realidade sociohistórica brasileira e incompreensível na cultura e na literatura nacionais: "O cultivo deste tópico constitui uma baliza a mais no desenvolvimento da escrita judaica no Brasil, embora seja um assunto estranho à cultura brasileira. Assim sendo, tem pouca ou quase nenhuma reverberação literária" (IGEL, 2000, p. 335). Daí, Regina Igel argumentar "problemas de categorização e de localização" (IGEL, 1997, p. 219) de um "fenômeno de prestígio íntimo na cultura brasileira" (IGEL, 1991, p. 55). A presença marginal da expressão literária de diferença, "ainda não inteiramente reconhecida pelos cânones literários - no curso vital da literatura brasileira" (IGEL, 1991, p. 56-57), foi inevitavelmente relacionada com a presença marginal da memória e da história do Holocausto no Brasil. Sua implementação viu-se como um desafio para o público brasileiro que possui uma "imaginação limitada pela realidade histórica, apegada a situações tangíveis pela memória" (IGEL, 1997, p. 219) e cuja "boa parte dos destinatários pode ser classificada como não-conhecedora ou mal-conhecedora do texto histórico e da mitificação posterior" (ROZENCHAN, 2001, p. 368), o que em efeito confinaria o tema "ao gueto" (SELIGMANN-SILVA, 2007, p. 138). O gueto - em qualquer contexto, mas neste em particular - possui um significado historicamente 
carregado e chama a atenção para uma situação de diferença e de marginalização, para a existência de fronteiras que separam e são impostas tanto pela cultura brasileira, sua realidade histórica e social, como pelo campo literário do Brasil:

\begin{abstract}
A presença da Shoah na Literatura brasileira é, devemos deixar claro logo de saída, extremamente marginal. Apesar da participação brasileira nas frentes de batalha da Segunda Guerra Mundial contra as forças nazistas, não se pode perceber na cultura deste país a presença forte deste fato. Mesmo hoje em dia, no início do século 21, com a importância atribuída pelos estudos culturais ao estudo dos relatos de sobreviventes e de minorias perseguidas, este panorama não mudou, ao menos com relação à Shoah. Os sobreviventes que por uma série de motivos variados acabaram aportando no Brasil, não encontraram aí um público acolhedor aos seus testemunhos. E, da mesma forma, o escritor brasileiro que eventualmente se voltou para este tema, tampouco respondeu a uma questão cultural vista como importante. (SELIGMANN-SILVA, 2007, p. 137)
\end{abstract}

No entanto, resulta que "o campo de estudos apenas em delineação" e a "bibliografia específica ainda relativamente escassa" (WALDMAN, 2003, p. 71), que não chegou a dialogar "com o veio da literatura nacional tradicionalmente mais valorizado" (SELIGMANN-SILVA, 2007, p. 154), teve sua chance de entrar no corpus da literatura brasileira bem antes da entrada do novo milênio, pelo menos segundo Robert DiAntonio. Analisando algumas obras de "expressão étnica judaica", o pesquisador chamou a atenção, entre outros, para certa estética que, segundo ele, esteve em alta desde os finais dos anos 60, possibilitando a integração dos temas judaicos no mainstream da literatura brasileira. Em princípio, trata-se da confrontação literária da experiência do trauma judaico com o ethos do Brasil como terra do futuro e da redenção. Portanto, a legitimação da literatura dessa temática dar-se-ia por vias da perpetuação de uma ideia que há muito tempo tem nutrido os discursos identitários, ideológicos e culturais no Brasil e sobre o Brasil. É difícil escapar à analogia com American Dream, expressão de crença no sucesso econômico e na liberdade pessoal; uma analogia que, contudo, escapa a DiAntonio na comparação da situação literária brasileira com a situação estadunidense dos anos 1960, quando "writers like Saul Bellow, Bernard Malamud, and Philip Roth brought the Jewish experience into the American mainstream" (DIANTONIO, 1991, p. 876). De todas as formas, o encontro entre o Holocausto e o ethos brasileiro, assim como apresentado por DiAntonio, não somente sugere um caminho teleológico, tão problemático no contexto do crime 
nazista, e uma superação da experiência traumática em favor da nova vida onde se pode seguir cultivando a judeidade (DiAntonio refere-se aqui em particular a Yiddishkeit), mas também confirma para o público brasileiro o mito do Brasil que já Ihe é familiar. Esse, portanto, não é o caminho para pensar a emergência, o seu potencial de ruptura, seu desafio aos discursos dominantes etc., mas um caminho, digamos, de assimilação - conceito que hoje em dia coloca mais dúvidas do que certezas.

Para sumarizar, observa-se que a literatura pós-Holocausto do Brasil tem sido sujeita a uma tripla marginalização. Ela foi confinada não apenas à margem da literatura brasileira, como notaram os pesquisadores aqui mencionados, mas também à margem da produção literária reconhecida no Brasil como judaica (literatura étnica, em palavras de DiAntonio, mainstream) e, além disso, não chegou a fazer parte da produção literária reconhecida como literatura do Holocausto. A solução para tal condição marginalizada não pode ser, porém, assimilação, mas uma afirmação da diferença que possa autorizar a literatura em questão e abrir para ela um espaço próprio, que seja, como já se demonstrou, na interseção entre vários conjuntos literários e com a preservação da autonomia estética e estrutural. Uma vez reconhecida sua autonomia, essa literatura torna-se um ator com o poder de participar não apenas dos espaços filológicos, como aquele da literatura comparada, mas também do espaço de memória pública no Brasil, contribuindo para o desenvolvimento deste espaço e deixando-se influir por ele. Finalmente, como o colocaria Bessière, essa literatura também ganha o poder de situar-se em relação à sua própria memória cultural e historiografia, "allowing connections between divergent histories and the structures of transmission they engender to emerge" e evitando ao mesmo tempo "obscuring important historical specificities and particularities." (HIRSCH, 2019, p. 175). A literatura pós-Holocausto do Brasil é uma literatura que se abre para vários discursos memorialísticos e se entrelaça produzindo novos conhecimentos, valores e sentidos, introduzindo novas práticas de rememoração multidirecional, assim como chamando a atenção para novas constelações intertextuais. E nisto justamente consiste seu traço emergente mais forte: polimorfismo da memória dos eventos traumáticos.

\section{Memórias entrelaçadas}

O chamado boom da memória no Ocidente, impulsionado pelo fim da Guerra Fria e pela redemocratização dos países do antigo bloco soviético, trouxe uma 
popularização dos estudos sobre a memória, o trauma e a cultura. Ele teve uma estrutura complexa e envolveu, por um lado, os imperativos nacionais e, por outro, as políticas de identidade, atravessando as fronteiras entre vários campos do conhecimento, nos quais havia o interesse pelo testemunho, memória e historiografia dos eventos coletivamente traumáticos. Esse processo incluiu a revisão crítica das ditaduras militares do Cone Sul, porém, significativamente menos no Brasil do que na Argentina, Chile e Uruguai, países onde a repressão sangrenta tem sido comumentemente chamada de genocídio (TRAVERSO, 2009, p. 35). A preservação dos depoimentos dos sobreviventes dos crimes ditatoriais no continente latinoamericano, assim como do Holocausto, tornou-se comum e extensivamente praticada, entre outros, devido ao desenvolvimento da tecnologia e à educação, especialmente universitária, resultando na produção de mais riqueza nas sociedades (WINTER, 2007[2000], p. 379). Como observou Huyssen (2003, p. 12), os discursos de memória foram, além de tudo, propiciados e estimulados pelo debate cada vez mais amplo sobre o Holocausto e a história da ascensão do nazismo na Europa. A emergência da memória do Holocausto numa escala global contribuiu efetivamente para a articulação de outras histórias, não, porém, numa direção unilateral como argumentado, por um lado, pelos críticos do paradigma do Holocausto como Walter Benn Michaels ou Andreas Huyssen (no contexto do Holocausto como screen memory), ou, por outro lado, pelos defensores da singularidade da Destruição como Stephen Katz ou Elie Wiesel. Propondo uma virada de perspectiva historicamente substanciada que outorga um dinamismo aos processos de memória, Michael Rothberg (2009, p. 3) observou que as memórias coletivas são continuamente sujeitas à negociação, empréstimos e referências cruzadas e, como o passado feito presente, elas são intervenções - ações sociais - produtivas, cujos atores trazem "multiple traumatic pasts into a heterogeneous and changing post-World War II present." (ROTHBERG, 2009, p. 4) Tendo isso em consideração, é possível constatar que a emergência da memória do Holocausto em si foi flexionada pelas histórias da escravidão, colonialismo e decolonialismo, entrando em diálogos pluriversais até com as ditaduras militares, como evidencia o caso dos países latino-americanos do Cone Sul, cuja literatura é o melhor exemplo deste processo multidirecional.

No Brasil, já nos anos 1970, isto é, em plena ditadura militar (1964-1985), observa-se uma presença de elementos da cultura e da história judaicas, inclusive da memória do Holocausto e da história do antissemitismo nos textos ficcionais sobre a 
ditadura militar. É possível relacionar esse fenômeno literário a uma ordem natural de expansão cultural dos imigrantes judeus dentro da sociedade brasileira, mas também em particular àquilo que diz respeito aos anos 1970, quando a presença dos sobreviventes do Holocausto vindos para o Brasil nos anos 1950 e 1960 ganha visibilidade (VIEIRA, 1986, p. 62). Essa nova constelação sociocultural, junto com a situação política no Brasil, contribuiu para o crescente uso de temas judaicos pelos escritores judeus e não-judeus. Ao associar a situação dos brasileiros durante a opressão ditatorial à resistência dos judeus alemães contra a repressão na Alemanha nazista, Vieira (1986) enfatiza o papel dos motivos e símbolos judeus na representação da opressão local e na luta contra ela. Nesse sentido, além de tudo, a experiência traumática do Holocausto serviria como metáfora para a representação do contexto local, indo além da experiência marcada pelo teor testemunhal, como é o caso de romances como Hitler manda lembranças (1984), de Roberto Drummond, Pessach: A travessia (1967), de Carlos Heitor Cony, ou alguns dos romances de Moacyr Scliar, como O Centauro no Jardim (1980) e A guerra no Bom Fim (1972). Essa prosa que denuncia a repressão política, a corrupção e o legado do colonialismo, - Holocausto e/ou a milenar história judaica de perseguição e injustiça, serve como veículo através do qual outras histórias de sofrimento coletivo podem ser articuladas:

The metaphorically Jewish nature of these Brazilian narratives as a literary act, points to the power and belief in the values of the Jewish people. With this act, there is hope for the maintenance of the Jewish tradition in Brazil, a tradition which can contribute to Brazil's and Latin America's struggle for survival against the inhuman inequities and historical paradoxes existing in the world as well as within Latin America's very own cultures. (VIEIRA, 1986, p. 70)

Embora as observações de Vieira sejam valiosas e abram já nos anos 1980 uma nova perspectiva para o estudo da literatura brasileira e da literatura judaicobrasileira, elas ainda insistem justamente no contrário do que propõe Rothberg com a memória multidirecional, nomeadamente na unilateralidade da relação entre as memórias traumáticas do Holocausto e da ditadura no Brasil. Portanto, no exemplo da literatura pós-Holocausto do Brasil, sugere-se implementar a dita virada de perspectiva, onde a ramificação metodológica de Rothberg possibilite uma reinterpretação do encontro entre duas distintas histórias da violência. Este encontro, cujo caminho foi talhado pela literatura já a partir dos anos 1970, como evidenciado 
por Vieira, intensifica-se a partir dos anos 1990 de uma maneira altamente versátil e inovadora, embora na maioria dos casos apenas sutil e alusiva, e longe de ser classificada como unilateral. O tal encontro precisa ser inscrito no fenômeno do boom da memória no Ocidente - inclusive no Brasil embora tardio - e abordado com o método da memória multidirecional. É possível que talvez se trate aqui de mais do que um método, isto é, de uma especificidade estética concreta e produtiva da literatura emergente em questão que rompe com o conhecimento pré-estabelecido sobre a literatura do Holocausto em geral e sobre o cultivo do tema do Holocausto na literatura brasileira.

Enquanto o conceito da memória multidirecional ocupa-se primariamente com as memórias coletivas dos eventos históricos, na literatura pós-Holocausto do Brasil observa-se um movimento em várias direções que se dá não apenas no plano de grandes traumas coletivos, mas também no plano de memórias particulares referentes ao universo íntimo e diário dos protagonistas, onde o Holocausto ganha e outorga novos significados mnemônicos. Portanto, para guardar o sentido original do conceito de Rothberg, propõe-se usá-lo como um ponto de partida para tratar de memórias entrelaçadas, com enfoque, porém, no diálogo dos legados de violência sistêmica. Observemos alguns exemplos.

No romance de Giselda Leirner, de 2007, Nas águas do mesmo rio, a perspectiva de classe social, que no contexto brasileiro é intimamente ligada ao legado colonial, está encapsulada na topografia da cidade de São Paulo. Aqui, a desigualdade social abordada através da questão de desalojamento entretece-se com a memória do Holocausto, quando o espaço no centro da metrópole brasileira ocupado pelos moradores de rua transforma-se num cronotopo do trauma concentracionário. Essa relação se vê ainda mais complexa na linguagem depreciativa utilizada pela narradora para se referir à pessoa sem abrigo em termos de "mendiga". ${ }^{4}$ As questões de desigualdade social estão também presentes no romance de Luis S. Krausz, Desterro: memórias em ruínas (2011), onde de novo aparece o cronotopo de São Paulo com sua paisagem urbana em constante transformação, que sob o leme do progresso empurra os mais pobres para as periferias da cidade. Aqui, a memória do Holocausto é proporcionada em vislumbres da catástrofe ambiental, também resultado do sufoco proporcionado pelo capitalismo

\footnotetext{
${ }^{4}$ Agradeço a Gabriel Philipson por me ter guiado na direção desta interpretação.
} 
e pelo crescimento urbano, assim como em reminiscências da ditadura militar e seus "capitães de indústria" (KRAUSZ 2011, p. 13). Em K. Relato de uma busca (2013), de Bernardo Kucinski, a memória judaica das calamidades irrompe no contexto dos crimes perpetrados pelo regime militar, e o tema da sobrevivência do Holocausto sobrepõe-se à dor de culpa do pai de ter sobrevivido à própria filha desaparecida pela ditadura. Já no romance de Cíntia Moscovich, Por que sou gorda mamãe (2006), as questões de discriminação racial são alegorizadas pela presença do corpo obeso que o sistema totalitário disciplina, exclui e extermina. ${ }^{5}$ Enquanto isso, a reminiscência suave da ditadura revela-se na confrontação indireta da censura com a necessidade de escrever, onde a escrita é a prática de luto e o último legado judaico. E enquanto para protagonista de Moscovich a escrita é a perlaboração do trauma - em vários níveis -, Tatiana Salem Levy, em A chave da casa (2007), utiliza o ato de escrever como a medida para se lidar com o enigma do passado que paralisa. Nessa autoficção pós-catastrófica, a narrativa transita pelos recantos da memória coletivamente traumática. A protagonista vive uma acumulação do trauma de desenraizamento devido à inquisição, guerras e ditadura. O corpo paralisado é aqui, como em Moscovich, recipiente da memória transgeracional onde se encontra introjetada a memória do que é indizível e inviável. Já no outro romance de Salem Levy, Paraíso (2014), um dos personagens é neto do sobrevivente de Auschwitz. Esse fio mantémse latente na narrativa que expõe outras memórias coletivamente traumáticas, como escravidão, violência doméstica e SIDA. Finalmente, Diário da queda (2011), de Michel Laub, coloca o assunto de memórias em competição, onde o genocídio dos judeus europeus daria apenas um capítulo (comum) na história da violência humana.

\section{Conclusões}

Os textos pós-Holocausto do Brasil formam um construto literário emergente que desestabiliza as noções e as condições do campo literário do Brasil confinado em paradigmas nacionais, históricos, da memória, da sociedade e da cultura. A emergência, nesse caso, inspirada pelas reflexões de Bèssiere acerca das literaturas francófonas, foi concebida em termos de ruptura, ato e potencial que possibilitaram observar os textos pós-Holocausto como aqueles que produzem novos conhecimentos, valores e significados, incitam reflexão sobre novas práticas de

\footnotetext{
${ }^{5}$ Mais sobre esse aspecto no romance de Moscovich escreveu Moacir Amâncio no seu artigo de 2008.
} 
rememoração e sobre as relações entre os textos e entre a história e o texto literário, e com isso participam da esfera pública da memória no Brasil. Torna-se, portanto, inevitável a criação de um novo espaço hermenêutico e epistemológico que é a literatura pós-Holocausto do Brasil.

A emergência dessa literatura viu-se condicionada pela pesquisa teórico-crítica que a delineou como uma expressão marginalizada, étnica e de temática alheia às realidades brasileiras. Portanto, com o objetivo de capturar as especificidades que constroem essa literatura como um corpus de potência para expansão e engajamento com outras literaturas, propôs-se o seguinte: primeiro, no lugar de pensar a margem, surge a opção de pensar a interseção como moldura para se capturar a heterogeneidade, intercâmbio e até certo ponto, se se quiser, o carácter de inbetweenness, observado já por Waldman (2003) e por Vieira (2009); segundo, no lugar da etnicidade normativa, que coloca no primeiro plano sobretudo a origem dos autores, sugere-se concentrar nas características textuais que destacam uma consciência judaica perante a tradição e a história flexionadas pela experiência traumática do Holocausto; finalmente, no lugar da distância, convida-se a considerar os emaranhados mnemônicos que aproximam o Holocausto a várias histórias coletivamente traumáticas de violência no Brasil: a ditadura, o colonialismo e a escravidão. O polimorfismo da memória, pesquisado com o método multidirecional, deve ser considerado como um traço marcante e contínuo dessa literatura emergente porque, com isso, ela consegue desafiar os discursos tradicionais e ainda persistentes sobre a memória e sobre o trauma no Ocidente. O caso da literatura pós-Holocausto do Brasil demonstra talvez que, hoje em dia, a perlaboração do trauma judaico junto com outras histórias coletivamente traumáticas é a chave para a descolonização do Holocausto (KLÄVERS, 2019) e a inclusão da sua história na história literária das sociedades pós-coloniais como a brasileira.

\section{Referências}

AIZENBERG, E. On the edge of the Holocaust: the Shoah in Latin American literature and culture. Waltham, Mass.: Brandeis, 2015.

AMÂNCIO, M. Os traumas e as mutações da memória (caminhos para a compreensão de um romance brasileiro. Revista de Literatura, História e Memória. 2018, v. 4, n.4, p. 29-38. 
ASSMANN, A. The Holocaust - a Global Memory? Extensions and Limits of a New Memory Community. In: CONRAD, S; ASSMANN, A. (org.). Memory in a Global Age: Discourses, Practices and Trajectories. Basingstoke, Hampshire: Palgrave Macmillan, 2010. p. $97-117$.

BERBERICH, C. The Continued Presence of the Past: New Directions in Holocaust Writing? Modernism/modernity. 2006, v. 13, n. 3, p. 567-575.

BESSIĖRE, J. Penser les littératures émergentes. In: FAESSEL, S.; M. PEREZ, M.(eds.). Littératures d'émegence et mondialisation. Paris: Press Éditions, 2004. p. 47-65.

BOURDIEU, P. The Field of Cultural Production. Essays on Art and Literature (trad. e ed. R. Johnson). Cambridge: Polity Press, 1993.

CHEYETTE, B. Venetian Spaces: Old-New Literatures and the Ambivalent Uses of Jewish History. In: NASTA, S. (org.). Reading the 'New' Literatures in a Postcolonial Era. Cambridge: D.S. Brewer, 2000. p. 53-72.

DIANTONIO, R. Redemption and Rebirth on a Safe Shore: The Holocaust in Contemporary Brazilian Fiction. Hispania. 1991, v. 74, n.4, p. 876-880.

GODZICH, W. Emergent Literature and the Field of Comparative Literature. In: KOELB, C.; NOAKES, S. (eds.). The Comparative Perspective on Literature. Approaches to Theory and Practice. Ithaca/ London: Cornell University Press, 1988. p. 18-36.

GOLDBERG, F. Literatura Judía Latinoamericana: modelos para armar. Revista Iberoamericana. 2000, v. LXVI, n. 191, p. 309-324.

GRIN, M.; GHERMAN, M. Identidades ambivalentes: desafios aos estudos judaicos no Brasil. Rio de Janeiro: 7Letras, 2016.

HIRSCH, M. Connective Arts of Postmemory. Analecta Politica. 2019, v. 9, n.16, p. 171-176.

HUYSSEN, A. Present Pasts. Urban Palimpsests and the Politics of Memory. Stanford, CA: Stanford University Press, 2003.

IGEL, R. O tema do Holocausto na literatura brasileira. Noaj/Noah. 1991, v.6, p. 5565.

IGEL, R. Imigrantes judeus, escritores brasileiros: o componente judaico na literatura brasileira. São Paulo: Perspectiva, 1997. 
KLÄVERS, S. Decolonizing Auschwitz? Komparativ-postkoloniale Ansätze in der Holocaustforschung. Berlin: De Gruyter, 2019.

KRAUSZ, L. S. Desterro: memórias em ruínas. São Paulo: Tordesilhas, 2011.

MOSZCZYNSKA, J. M. Clarice Lispector e a latente escritura do desastre. Arquivo Maaravi: Revista Digital de Estudos Judaicos da UFMG. 2017, v. 11, n.21, p. 85-105.

ROSKIES, D. G.; DIAMANT, N. Holocaust literature: a history and guide. Waltham Mass.: Brandeis University Press, 2013.

ROTHBERG, M. Multidirectional memory remembering the Holocaust in the age of decolonization. Stanford, Calif.: Stanford University Press, 2009.

ROZENCHAN, N. Imaginário judaico na literatura brasileira: Genocídio. In BEJARANO, M. et al. (org.). Judaica Latinoamericana. Estudios Historico-Sociales. 2001, v. IV. Jerusalem: Universidad Hebrea, p. 367-379.

SELIGMANN-SILVA, M. Escrituras da Shoá no Brasil. Noah/Noaj. 2007, v. 16-17, p. 137-156.

SICHER, Efraim; WEINHOUSE, Linda. Under Postcolonial Eyes: Figuring the "Jew" in Contemporary British Writing. Univ. of Nebraska Press, 2012.

SULEIMAN, Susan R. Crises of Memory and the Second World War. Cambridge, MA/ London, England: Harvard University Press, 2006.

TRAVERSO, Enzo. Vom kritischen Gebrauch der Erinnerung. In: FLIERL, T.; MÜLLER, E. (org.). Vom kritischen Gebrauch der Erinnerung. Berlin: Karl Dietz Verlag, 2009. p. 27-46.

VIEIRA, Nelson H. Contemporary Jewish writing in Brazil: an anthology. Lincoln: University of Nebraska Press, 2009.

VIEIRA, Nelson H. Post-Holocaust Literature in Brazil: Jewish Resistance and Resurgence as Literary Metaphors for Brazilian Society and Politics. Modern Language Studies Modern Language Studies. 1986, v. 16 n.1, p. 62-70.

WALDMAN, Berta. Entre passos e rastros: presença judaica na literatura brasileira contemporânea. São Paulo: Perspectiva, 2003.

WINTER, Jay. The Generation of Memory: Reflections on the "Memory Boom" in Contemporary Historical Studies. Archives \& Social Studies: A Journal of Interdisciplinary Research. 2007, v. 1, p. 363-397.

WILLIAMS, Raymond. Marxism and Literature. Oxford University Press, 1977. 
Recebido em 23/10/2020 Aceito em 15/11/2020

Publicado em 20/12/2020 